This is an author's version of a chapter from The Recovery of People with Mental IIIness. Ed A. Rudnick. OUP. 2012. Pp. 217-235

\title{
Chapter 14: Being ill and getting better: recovery and accounts of disorder
}

- Rachel Cooper

\section{Introduction:}

Recovery from, or in, mental illness is taken to mean different things in different contexts (for a review see Bonney and Stickley 2008; Davidson, O'Connell, Tondora et al 2005). This chapter focuses on one important meaning of "recovery", according to which one recovers once one no longer has a disorder. Clearly this is not the only notion of recovery in use, and other chapters of this book concentrate on other notions of recovery. In concentrating on the sense of recovery whereby recovery occurs once one is no longer disordered, I do not wish to imply that other notions are unimportant or illegitimate. They are simply not what I focus on here.

In this chapter I explore how one's view of what counts as recovery (in the sense whereby the recovered person is one who ceases to be disordered) will depend on the account of disorder that one adopts. As has become usual in the literature on concepts of disorder, in talking of "disorder" here I lump together all diseases, illnesses, injuries and disabilities, and will consider mental and physical conditions together. Accounts of disorder can be split into two main categories. Descriptive accounts (paradigmatically Christopher Boorse's 1975, 1976, 1977 , 1997) claim that disorder is purely a matter of biological (and/or psychological) dysfunctioning. Such accounts are "descriptive" in that they imply that whether a condition is a disorder is simply a descriptive matter, that is it depends solely on value-free facts. On such accounts disorders are dysfunctions, and the route to recovery is the restoration of normal functioning. In contrast, accounts that hold 
that disorder is a value-laden concept will lead one to view recovery differently. On such accounts, for a condition to count as a disorder it must be bad. I will argue that whether a condition is bad will vary with factors such as the social environment, and also on the aims, desires, and self-understanding of the individual patient. A consequence of this is that a condition that was once bad for the patient can be rendered neutral or good not only by altering biological or psychological functioning but also by altering the patient's social environment or self-assessment of the situation. I end by considering the implications of the discussion for the assessment of recovery.

\section{Accounts of disorder \\ Descriptive accounts}

In this context, accounts of disorder can usefully be split into two main camps. Descriptive accounts claim that disorder is purely a matter of biological and/or psychological dysfunctioning. Such accounts have been best worked out by Christopher Boorse $(1975,1976,1977,1997)$. On Boorse's account we can think of the human body and mind as a goal-directed system that is made up of a number of subsystems. The goal of the organism as a whole is to survive and reproduce. "Subsystems" are taken in the broadest sense possible and include not only the solid organs of the body such as the liver, but also more diffuse bodily systems, such as the nervous system and skin. In his different publications, Boorse is not consistent as to whether his account should be extended to include mental disorder or not (1975 considers mental illness alongside physical illness, whereas in 1977 Boorse restricts his account to physical conditions). But given that Boorse extends his account on occasion, and given that he gives no principled reason for resisting such an extension, I will also consider a Boorsean account to apply to mental disorder. For Boorse's account to apply to mental disorder it will need to be the case that we can think of the brain and mind as consisting of subsystems that have some normal range of functioning. Such subsystems would consist of the different systems of the brain, 
and also mental modules, such as the system that facilitates face recognition. On Boorse's account, each bodily or mental subsystem has what can be deemed its normal function, which is whatever it standardly does that contributes to the organism achieving its overall goals. Thus the heart has the function of pumping blood round the body, the face recognition module has the function of enabling the recognition of faces and so on.

Boorse notes that the ways in which we can expect a human's subsystems to function will vary with sex, age, and maybe ethnic group. The functioning that we can expect is thus relative to a "reference class" - that is the group of humans to which we can fairly be compared. We can imagine Boorse's vision of the correctly functioning human being operationalised by a textbook of normal physiology and psychology. Given the sex and age of a person we could go to the relevant pages and find a "blueprint" that outlined what the statistically normal ranges would be for the functioning of such a person's subsystems. A physiological diagram would tell us the normal structure and measurements of the person's bones, and we would be supplied with charts giving normal ranges of blood pressure, measures of memory and so on. A healthy person would fit the appropriate blueprint, and each of his or her subsystems would fulfill its function.

On Boorse's account disorders occur whenever a subsystem fails to fulfill its function. Whenever the functioning of some subsystem falls below the norm compared with the functioning of similar such subsystems in the organisms that make up the "reference class", the affected person has a disorder. Boorse's account of "normal function" struggles to accommodate the possibility of universal disorders - such as dental caries, which is statistically normal and yet still plausibly a disorder. Boorse sometimes adds a condition that allows for the possibility of universal disorders, such as dental caries, in cases of environmental adversity, in this case, living in a sugar rich environment (Boorse, 1975, p.59, but 
see also Boorse,1997, p.86 where Boorse expresses doubts about this solution to the problem of universal disorders).

In the philosophy of biology, a rich literature concerns the correct account of "normal function" (see, for example, Ariew, Cummins and Perlman 2002). Boorse's account of "normal function" has much in common with the approach proposed by Robert Cummins (1975). Cummins-style accounts consider the function of some subsystem to be whatever it currently usually does that contributes to achieving the goals of a larger causal system. Thus, for Boorse, the function of the heart is to pump blood round the body, as this is what such subsystems currently usually do that contributes towards the organism-level goals of survival and reproduction. Other accounts are also possible. Most notably Larry Wright proposes an account whereby normal function depends on history (Wright 1973). In the case of biological functions, the function of a subsystem will be whatever it has been naturally selected to do. The function of the heart will still be to pump blood, but on Wright's account this is said to depend on evolutionary history (while on Cummins' account it depends on current causal relationships). Corresponding to the alternative accounts of function, there are different possible disorder-as-dysfunction accounts. Someone who disagrees with Boorse's account of function could still agree that disorders are dysfunctions, but employ whatever account of function they adopted to identify dysfunctions.

A key aim of Boorse's account is to provide a value-free account of disorder. (An account that agreed that disorders are dysfunctions but employed a Wright-style account of function would also yield a value-free account of disorder). Boorse thinks that whether someone suffers from a disorder depends purely on matters of biological and psychological fact. Not only does Boorse think that a diagnosis of disorder can be made independently of any value-judgments, he also thinks that a diagnosis has no value-laden implications. A Boorsean diagnosis is supposed to leave the question of whether treatment might be desirable (or not) completely open. This comes out particularly clearly in Boorse's discussion of 
homosexuality (1975). Boorse holds that homosexuality is a disorder - as he considers that some mental subsystem is failing to fulfill its function of ensuring sexual attraction to members of the opposite sex, with disruptive consequences for the reproductive fitness of the person. Still, Boorse holds that though homosexuality on his account is a disorder, this implies nothing whatsoever about whether it is a bad or good thing, and consequently has no implications for questions about the desirability of treatment. On a Booresean account, given that a particular case of disorder may or may not be a bad thing, seeking recovery, in the sense of getting rid of the disorder, may or may not be advisable.

\section{Value-laden accounts}

Many theorists think that Boorse's descriptive account is misguided, and that whether someone is healthy or disordered is essentially a value-laden matter. The motivation for such accounts can be seen most clearly via considering Boorse's views on homosexuality. Boorse states that homosexuality is a disorder but that this has no moral or political implications. To many this seems unsatisfactory. Calling something a disorder but adding that nothing need be done about it, is a contradiction, they think. To such theorists our concept of disorder is essentially value-laden. To say that a condition is a disorder is to imply that it is a bad thing.

It is important to note that those who hold a value-laden account of disorder form a motley group. Though members of this group agree that disorder is a valueladen concept, different theorists combine the requirement that disorders be harmful with other criteria that must be satisfied for a condition to count as a disorder. Jerome Wakefield holds an account similar to Boorse's but adds a criterion that disorders must be harmful (Wakefield 1992a, 1992b, 1993). Lawrie Reznek has argued that a condition is pathological if and only if it is an abnormal bodily/ mental condition which requires medical intervention and which harms standard members of the species in standard conditions (Reznek, 1987, pp.163- 
4). I have argued that disorders are conditions that it is a bad thing to have, that are such that we consider the afflicted person to be unlucky, and that can potentially be appropriately medically treated (Cooper 2002). Others who hold that disorders must be harmful propose various other accounts (Fulford 1989; Nordenfelt 1987; Richman 2004).

To this diversity, an added complication must be added. There are many accounts of harm. To give just some indication of the range of possible views, on some accounts whether a person suffers harm depends on his or her selfassessment, on other accounts the judgments of the individual's community matters, on other accounts whether someone is harmed depends on objective facts as to whether he or she can flourish as a human being ideally should (for an overview see Griffin 1986). The difference between these accounts can be seen clearly if one considers what they would say about a woman who has been rendered incapable of feeling sexual pleasure via female "circumcision". In certain cultures the circumcised woman is as her community thinks she should be, but on an idealised account of human capacities she can still be considered to have been harmed. Whether she herself disvalues her condition is of course a third question. While all those who hold that disorder is a value-laden concept agree that disorders must be harmful, because they disagree on the correct account of harm, and also because they disagree on what other criteria (if any) must be satisfied for a condition to count as a disorder, there are many, not one, value-laden accounts of disorder.

For our purposes, however, it is sufficient to note the following: On value-laden accounts of disorder, a condition is only a disorder if it is harmful. This implies that someone can be biologically or psychological unusual, and indeed some subsystem may fail to fulfill its function, but so long as this causes no harm, this is a mere difference, not a disorder.

\section{Implications for notions of recovery}


In this chapter I will not argue for any particular account of disorder, but merely chart the implications for a concept of recovery if adopting a descriptive or alternatively a value-laden approach. As previously noted, notions of recovery are contested, but on at least one concept of recovery, a person recovers when he or she ceases to have a disorder. Accounts of disorder are thus relevant because, depending on the account of disorder one adopts, there will be different possible routes to recovery. On a descriptive account, whenever there is a dysfunction there is a disorder, and so recovery will require the restitution of normal functioning. On value-laden accounts of disorder, for something to be a disorder it must be harmful. Thus, it might be possible to treat a disorder, not by altering biological or psychological functioning, but by making it the case that a condition that was harmful ceases to cause harm. Here we shall consider each type of possibility in turn.

\section{Recovery by Restoring Functioning}

On a Boorsean account the only way to get rid of a disorder is to fix the subsystem that is performing in a below average fashion. Paradigmatically, the doctor fixes a patient in the same sort of way that a car mechanic might fix a car: If a valve is broken then the mechanic takes it out and puts in a replacement, thus mending the car. Similarly, if a heart valve performs poorly it might be replaced, thus fixing the patient. Even when medicine doesn't act to replace subsystems, the aim of a Boorsean physician is to restore health via restoring normal functioning to the subsystems that are performing below anticipated levels. Within psychiatry, many psychoactive medications are marketed as working in something like this way. Disorder is seen as stemming from a fault in one or more particular subsystems - some neurotransmitter is being over- or under-produced, and the drug promises to solve the problem and restore functioning. 
The Boorsean picture encourages us to think of human beings as being made up of subsystems which need to be made to function normally for a person to be healthy. However, even if we stick to thinking of disorder in purely biological and psychological terms such a perspective is plausibly too narrow. In his 2000 paper, "Against Normal Function", Ron Amundson argues that in concentrating on the operation of parts of the body and mind, the Boorsean physician risks missing the big picture. Amundson draws our attention to cases where biologically unusual organisms adapt in ways such that the functioning of the organism considered as a whole approaches normal levels although the functioning of individual subsystems may remain grossly below par. Most memorably, Amundson discusses a goat born without front legs, which was studied by the biologist E.J. Slipjer in the 1940s. In addition to its missing legs, the goat differed from the normal anatomy of goats in numerous ways. It had an S-shaped spine, a misshaped thorax, and many other abnormal bones and muscles. The Boorsean picture encourages us to look at the goat subsystem by subsystem. On this model we see nothing but problems, which a Boorsean model encourages us to think of additively, with each abnormality taking the goat further and further away from the healthy normal standard. However, on such a part-based view we miss out something important - Slipjer's goat had learnt to walk on its back legs. Considered as a total system, the goal of which is to survive and reproduce, the goat didn't do too badly. If we consider the goat as a whole we see that although each subsystem may be grossly unusual, together they operate fairly well.

Amundson's paper shows that even if a part of an organism dysfunctions, this need not imply that the organism considered as a whole dysfunctions. This point is important, and appears to have been over-looked by Boorse, but I think it could be incorporated into a purely descriptive account of disorder. Boorse does say that on his account where a system dysfunctions there is a disorder, but it would be quite easy for him to revise this claim and to acknowledge that in certain cases a number of subsystems that are individually dysfunctioning can act 
together to form a passable whole. For Boorse the ultimate aim of the organism is to survive and reproduce, and where an organism has no problems at these levels, it would be within the spirit of the Boorsean programme to say that there is no disorder.

Amundson shows us that if we consider the organism as an integrated whole rather than as collection of subsystems an unusual organism may not be badly off. This insight enables us to think of the range of possible medical treatments being extended and increases the possible routes to recovery. In addition to having treatments that work via fixing individual broken subsystems, it may be possible to have treatments that operate via altering the functioning of other subsystems in such a way that the original oddity is compensated. For example, some people with autism learn to function passably well in social interactions, but their route to success may be unusual. In an interview with Oliver Sacks, Temple Grandin, a successful scientist with autism, talks of how she learnt how to act in social situations (Sacks 1995). Grandin says that she watched how people behaved in different circumstances, and tried to remember what they did. She now has a sufficient remembered "library" of scenarios that she can predict with some success how she is expected to act and how others will act in different settings. Grandin is still socially awkward, but we can imagine people who might achieve acceptable levels of social functioning via such unusual means. At the level of the overall person in such cases there would be no dysfunction.

The moral to be drawn from Slipjer's goat is that it's the functioning of the organism rather than its individual subsystems that really matters, even from a viewpoint that is compatible with Boorse's approach. In considering the functioning of human beings we may be able to take things yet further. We can note that it is natural for humans to use tools to enable them to achieve ends that would otherwise be unachievable. If we are interested in how well a person manages to achieve his or her life goals then the proper unit for consideration may not be the naked human but rather the system that consists of that naked 
human and the tools that are reliably at his or her disposal. Most simply this possibility can be illustrated if we think of technologies like contact lenses. Some short-sighted people have their biological eyes fixed with laser treatment; other short-sighted people use contact lenses. These two approaches to dealing with the problem have different costs and benefits associated with them - contact lenses have to be put in and taken out, laser surgery can go wrong, and so on. However, if we are interested in how well the person can see, for practical purposes the contact lens user and the laser-treated person may be on a par. If we take the functional unit of interest to be naked-human-plus-tools we might say that both people have equal sight and hence equal health (other things being equal).

Such a view fits naturally with some trends of thought in disability studies. Thus we can say that, in so far as the environment is suitable for wheelchair use, the wheelchair user is not mobility impaired. The unit that consists of the human being plus the wheelchair is able to get around fine. Similarly, a Deaf person living in a signing community, who has access to technologies such as visual fire alarms and TV subtexting, may have no relevant health related problems.

The view that the right functional unit to consider is human-plus-tools is easiest to apply when thinking of physical disabilities and the gadgets that humans can employ to turn themselves into well-functioning systems. However, it may be possible to extend such views to think about mental disorders. In a much cited 1998 paper, Andy Clark and David Chalmers argued for the view that cognition does not occur simply in our heads but also extends into the world. Clark and Chalmers say that when a writer jots notes on scraps of paper, when a scrabble player shuffles letters to see what words can be produced, and when an engineer manipulates models of buildings, we can see their cognition as extending into the world. In addition to the brains, the paper, the letters, and models form part of the physical underpinning of the cognition that occurs. In cases where a tool comes to be used by a human to facilitate thinking in a way that is constant, reliable, and 
implicitly trusted, Clark and Chalmers say that we can think of that tool as being part of the person's mind. Clark and Chalmers discuss the case of a person with brain-related memory problems who uses a notebook to record matters to be remembered. In so far as the notebook can fulfill the function of the damaged brain-related memory, they say that the notebook can be considered to be part of that human's mind.

If we adopt such a view, the possibilities for treating disordered persons extend beyond the biological and psychological. Technologies might replace malfunctioning subsystems, and the human-plus-technology unit may thus be restored to adequate functioning. Clark and Chalmer's case of a broken memory being substituted with a notebook or computer-based memory store is the most obvious example. Drayson and Clark (forthcoming) consider further the possibilities of the extended cognition paradigm for thinking of treatment of memory problems. Our control of emotions and impulses might also be improved by the use of external gadgetry. Emotional changes have physiological correlates and so it might be possible to create devices that detect these changes and operate so as to bring them back under control. For example, suppose that I struggle to control my temper. A device that detected my emerging anger might form part of a system enabling its control. We can imagine more or less automated mechanisms. At the less automated end of the spectrum, a simple warning that my anger-levels were rising might be sufficient to prompt me to initiate anger-management techniques. Alternatively, an automated injection of calming drugs might be used to curb my aggressive impulses. Either way, the human-plus-technology system might have no anger management problems. We can imagine other problems of impulse control being dealt with similarly. Clearly more automated systems lend themselves to coercive forms of treatment, but it is worth noting that they are not intrinsically coercive, and some people would choose to use such systems. If we consider the basic unit of interest to be the human-plus-tools unit then normal levels of functioning might be restored via altering the non-human parts of the system. On such a view, recovery may be 
facilitated as much by engineers and computer scientists as by physicians and other clinicians.

We have seen that even if we stick with the idea that the way to treat a disorder is to seek to restore normal functioning, there are a range of types of recovery that correspond to normal functioning being restored at different levels of functional analysis. On Boorse's model, disorders are dysfunctions of subsystems. If we consider functioning at the subsystem level, recovery can be achieved via restoring the functioning of the subsystem. We can also think of recovery as being achievable via restoring functioning at the organism level, even when individual subsystems continue to operate unusually. Slipjer's goat shows that unusually operating subsystems can come to act together to achieve satisfactory functioning at the organism level. Finally, if we think of the humanplus-technology unit as being the appropriate system of interest, then normal functioning might be restored even when the human organism is left as before, via the use of various technologies to compensate for biological and psychological differences.

\section{Recovery by Ameliorating Harm}

For someone who wants to stick to a purely descriptive account of disorder, disorder occurs when there is a dysfunction, and recovery can only be achieved via restoring functioning (at some level or other). On value-laden accounts of disorder there may be alternative routes to recovery. On a value-laden account a disorder must be harmful. Writers disagree as to whether the harmfulness of a condition should be considered on an individual basis or at some other level. I have argued that harm should be assessed on an individual basis (Cooper 2002). I think that what matters is whether a condition has a tendency to harm the affected individual. Others who adopt value-laden accounts of disorder think that harmfulness should not be assessed at the individual level. For example, 
Reznek (1987) holds that disorders must harm "standard members of the species in standard conditions" (pp.163-4). The big problem for someone adopting such a line will be to flesh out the meaning of "standard members" and "standard conditions". The dispute will not be resolved here, but we can note that on accounts that claim that harm should be assessed at the individual level it will be possible to cure someone by making a previously harmful condition harmless for that individual. On accounts that hold that a condition is a disorder if it is harmful for many or most affected people it might also be possible to cure people by rendering harmful states harmless, but in so far as making the lives of lots of people better is more difficult than helping individuals this will be more difficult.

As noted earlier, providing an account of harm is very difficult. That the issues are challenging can be seen most clearly when one considers that giving an account of the harmed life is the flipside of giving an account of the good life. And working out what counts as a good life is, of course, one of the hardest and most perennial of philosophical problems. Many of those who work in the social sciences are tempted by views that tie harm to evaluations by affected individuals or their communities. The basic idea is that if you want to know whether a state harms individuals you should ask those individuals how they feel about it. This approach is attractive because it makes notions of harm operationalisable (ie one knows how to figure out if a state is harmful), and it allows individuals to judge their own states, thus avoiding worries about paternalism. Problems with this approach are not hard to see however. As humans, we frequently make mistakes about our own good. We are commonly foolish, self-deceived, lazy, lacking in imagination, tired, ignorant and biased, and also scarily prone to addictions, delusions and compulsions. As a result, we frequently make mistakes when evaluating our own physical and mental states. Consider the obese person who can't get outside, but claims to be quite happy staying in and watching the TV. Or someone who has always been tired and thus accepts such a state as normal. Or a person with delusions who believes himself privileged to be the son of God. In such cases we hesitate to accept the 
individuals' evaluations that they are doing just fine. Turning to consider the judgments of communities instead of individuals won't help either. Communities are also often wrong. Whole societies have considered sexually expressive women, masturbating children, and disobedient slaves to have health problems that needed treating.

In evaluating whether a state is harmful we should be wary of relying on the opinions of actual people. But what other options are available to us? We might develop an account that depends on idealisation. Rather than the good life for individuals being what they actually judge to be good, it might be what they would judge to be good if they were better informed, calmer, and cleverer. Alternatively, on Aristotelian accounts, human beings are such that there are objective facts of the matter as to the sorts of lives that are good for humans. For example, the Aristotelian may say that humans are naturally social creatures. In the same sort of way that herd animals naturally live in groups and it would be cruel to keep one alone, humans are naturally such that they need friends and any state that makes friendship impossible for a human is harmful, regardless of what the affected individual claims. Such a view may sound arrogant, in so far as the Aristotelian thinks that the affected individual can simply be mistaken in judging his or her life. However, it is important to note that although Aristotelians may claim that there are objective facts about what humans need in order to live a good life, they don't claim that they themselves have infallible knowledge as to what these facts might be. Such Aristotelians accept (or at least logically should do so) that they themselves may turn out to have made mistakes in evaluating the quality of their lives.

One prominent neo-Aristotelian approach is the capabilities approach as developed by Amarta Sen and Martha Nussbaum (Sen 1980, 1993; Nussbaum 2000). On this approach, a good life is thought to be possible only if people have opportunities to exercise various capabilities. The list of capabilities may be contested, but Nussbaum suggests that humans are such that opportunities for 
goods like friendship, education, play, interacting with the natural environment, and participating in political action (amongst other goods) will be important (Nussbaum 2000). On such a view we may judge whether individuals have good lives by considering their opportunities for exercising human capabilities. The difficulty for such accounts is arriving at the list of capabilities.

Arriving at the correct general account of the good life, and thus of harm, is problematic. In the meantime, however, we may be able to make progress in evaluating particular controversial conditions because there is broad agreement about many particular states being either good or harmful. No one seriously doubts that, all things being equal, states such as being in pain, having no sense of humour, and being unable to communicate, are harmful. Conversely there is broad agreement that states such as experiencing pleasant sensations, being able to run around, and being able to sleep at night are good. With such widespread consensus about particular states, in most cases we can be fairly confident in saying whether a biological or psychological difference is harmful or not. Many cases will be straightforward to assess. Colds make us feel achy and make our noses run. They have no redeeming features and are thoroughly bad things. Other cases may be more problematic. Maybe we are unsure exactly what effects a condition has, for example the health consequences of moderate obesity are contested. Sometimes a condition may produce both benefits and harms and determining how to weight these may be difficult, for example weighing the highs against the lows in manic-depression may be problematic. Sometimes we may know what the effects of a condition are but not know how to evaluate them, for example it may be hard to decide whether a deep-seated concern for others is morally praiseworthy or neurotic.

An added complication in using our commonplace intuitions about goods and harms to assess the effects of biological and psychological differences is that the experiences of the biologically and psychologically atypical may on occasion force us to revise our beliefs concerning the good life. There is thus a two-way 
interaction between our intuitions of the good life and our evaluations of various states. For example, we may start by assuming that intelligence contributes to living a good life, but close acquaintance with those who are intellectually disabled but happy, and with those who are very clever but unhappy, may prompt us to revise our assumptions. Or, to take another example, suppose we set out by thinking that being unable to talk must be awful, as we assume that such people will be cut off from communicating with their fellow human beings. Then we encounter the sign languages used by Deaf communities and this expands the possibilities we can imagine. We see that it is possible to have non-oral languages, and revise our assessment of the harms cause by not being able to speak. Instead of thinking that it is terrible not to speak, we think that it is terrible not to be able to communicate. The interactions between our view of the good life and our experiences of biological and psychological difference are thus complex. In many cases the views of those who have experienced difference can help to educate our views of the good life. If people who are different say that they like being as they are we should take them seriously. However, the risk of selfdeception means that the claims of those who experience difference cannot simply be taken at face-value, but must be subjected to critical assessment.

Working out whether a condition is harmful can sometimes be problematic but is often relatively straightforward. What, then, can we say about the relationship between harm, treatment and recovery?

Most obviously, if a condition does no harm there is no need to treat it (whether neutral states might yet be enhanced is a different question, and is beyond the scope of this paper). All those who have written about the concept of disorder are agreed that harmless states do not require treatment. On the Boorsean account dysfunctions that do no harm count as disorders, but they are disorders that do not need treating. On accounts that hold that disorders are necessarily bad, a dysfunction that does no harm is not a disorder but a mere difference. One might think that it goes without saying that harmless states can be left untreated. 
However, plausibly there are cases where medicine has become so fixated on restoring "normal functioning" that the fact that being atypical need not be a problem has been forgotten. The clearest examples of these tendencies can be seen in the treatment of infants who are born with atypical bits and pieces. Intersex babies tend to have surgery to normalize their genitals, extra fingers may be lopped off, and fused toes separated, and plausibly in some cases such procedures pursue normalization as if being normal was itself a good, without considering whether the unusual states will actually cause biological or psychological harm and thus require intervention (Amundson 2000; Dreger 1998).

Turning to consider links between harm and recovery, if one adopts an account of disorder according to which disorders are necessarily harmful for the individual, one will think that it may be possible for someone to recover, even if his or her biological and psychological mechanisms are left unchanged, if something else happens that makes it the case that the state that used to cause harm ceases to do so. We can imagine this occurring in a number of different ways.

Most simply, the individual may come to like his or her condition. Views of the good life that hold that someone has a good life simply because he or she assesses it to be good are implausible because it seems that we often make mistakes in evaluating our lives. This being said, one's subjective assessment of one's state plays a role in determining whether one has a good life. This is because thinking that one's life is bad is plausibly in itself a bad thing. Scars and other physical oddities here offer the obvious case where a change in the way in which the affected individuals evaluates their state may make all the difference. Some people are very distressed by their scars or physical differences even though others may have a fairly neutral view of them. In such cases individuals can cease to have a disorder purely and simply because they cease to disvalue their condition. 
A somewhat more complex case occurs when a condition ceases to cause harm, not because the affected individual revises his or her opinion of it, but because the values of the broader society change. Suppose that at one time a society as a whole finds female facial scars disgusting. Scarred women are shunned, and as a consequence become lonely and depressed. Then the values of the culture change and scars become fashionable. In such a case the scarred individuals may cease to have a disorder, not as a consequence of their condition changing but as a result of re-evaluation by the rest of society. Note that one can draw these conclusions without holding that whether a condition is bad depends wholly on how the members of that community evaluate it. So long as one accepts that part of what makes some conditions problematic is the responses of society then one will have cases where a shift in social attitudes may lead to recovery. This is consistent with a community sometimes being wrong in its evaluation of harm.

Techniques of symptom management can help to make a condition that was previously intolerable now manageable. Whether we should count such cases as recovered or not depends, I think, on the details of the situation. In some cases, managing symptoms can be hard work. We wouldn't normally consider those with diabetes who have to test their blood regularly and self-inject with insulin to be recovered - rather we'd say that their symptoms were managed. We should say the same about anyone who keeps the symptoms of a psychiatric illness under control by means that are similarly difficult. At the other end of the scale there are people who manage their symptoms via methods, which although they may feel like hard work to them, would count as basic self-care to most. Take the case of someone who finds that depression can be kept at bay by maintaining regular exercise, avoiding too many late nights, and reducing alcohol consumption. Depending on previous lifestyle, such self-care may feel like hard work; however, I suggest we should consider that he or she is recovered, and was previously not looking after him or herself. In between these two types of 
extreme cases there is a grey area, where people control symptoms in ways that are not very disruptive.

The sorts of bodies and minds that will be useful to us vary with our goals, activities, and social context. This means that when goals, activities or social context change, a condition that at one time caused harm may cease to be harmful. Let's first consider shifts in social demands. In literate societies dyslexia is a problem, but although some stone age people may have had dyslexic brains, struggling to read and write would have caused them no difficulties as there was no reading nor writing in their time. In such cases, if we hold that disorders have to be harmful, we should say that although there may well have been dyslexic people throughout history, dyslexia is only a disorder in certain environments. In saying that the harmfulness of a condition varies with environmental demands, and that thus when an environment changes a condition that once caused harm can cease to do so (and vice versa), we should probably require a certain level of robustness before we declare that someone has recovered as a result of environmental change. Suppose I have a snake phobia, but am fine when on holiday in Ireland, because I know that in Ireland there are no snakes. When I return home I am once again too afraid to leave home. Was I recovered while on holiday? I think we should say that I was not - my embedding in an environment in which my phobia caused no harm was not sufficiently robust. In contrast, stone age dyslexics were at no risk of being harmed by their condition. Their dyslexia was thus no disorder. Obviously there will be a grey area where we are unsure how securely individuals are embedded in an environment where their condition does no harm.

What about cases where an individual changes life goals and activities in such a way that a condition that at one time caused difficulties ceases to do so? Often peoples' goals and activities change as they restructure their lives after an episode of severe mental illness. Take the case of a corporate lawyer who enjoys career success, works seventy-hour weeks, and has no time for family, friends, 
or hobbies. Let's suppose this person suffers from an acute psychotic episode, and after the acute episode passes restructures her life. She now works parttime in a poorly paid job, writes poetry, and regularly plays golf. By avoiding additional stresses, she may remain symptom free. Evaluating this shift in lifestyle may be difficult for both the individual concerned and also for onlookers. Should we say that illness forced the ex-lawyer to settle for a lower-level of functioning? Or, has the experience of illness led to her re-evaluating her priorities and now living a richer, though less financially successful life? A judgment is difficult to make because it is very difficult to say what sorts of life are best, or, as noted above, what is a good life. It is hard to know how to weigh career success against opportunities for leisure-related creativity against having many friends (assuming they are not compatible, at least not easily so). In judging our own lives, additional complications arise because we are prone to self-deception and making post-hoc justifications. If I can no longer work, but spend my days writing poetry instead, I'm likely to start arguing that the creative life is better than working as a cog in a capitalist system. If I'm later forced to conclude that my poetry is no good, then it should be no surprise if I start to entertain the thought that it's the creative process rather than the creative output that really matters. Whether my experiences have brought me new wisdom, or whether self-deception now prevents me from recognizing my reduced level of functioning is extremely difficult to judge. It should be noted that my comments here do not apply only to mentally ill people. We are all prone to concluding that the grapes we can't reach are sour. There may be no general criteria that can be used to decide whether the person who radically revises his or her goals and aspirations after experiencing illness and claims that his or her new life is better than the old life has become wiser or is now self-deceived. Judgments may have to be made on a case by case basis.

Within the recovery movement one frequently comes across claims that one can be said to have recovered if one manages to have a good life despite having a mental disorder (eg Slade 2009; Schrank and Slade 2007, Davidson, O'Connell, 
Tonodra et al 2005). On such views, if I am occasionally confined to bed during depressive episodes, but judge that on balance my life is good and meaningful, I may be said to have recovered. In this chapter I have examined the concept of recovery in the sense of recovery whereby one recovers once one no longer has a disorder. Clearly, in this sense of recovery, one who has a good life, but has a disorder which still causes some problems, has not recovered.

I have now finished outlining the ways in which different accounts of disorder give rise to different accounts of recovery (in the sense of no longer having a disorder). Before going on to consider implications for assessing recovery, it may be useful to summarise the discussion so far. On descriptive accounts of disorder, recovery is to be achieved via restoring functioning, and we have seen that this might be achieved at a variety of different levels (subsystem, organism, human-plus-tools). On accounts of disorder that hold that disorders are necessarily bad it will be possible to get rid of disorders by making it the case that a state that previously caused harm ceases to do so. It is worth noting that, in practice, adherents of the two sorts of account need not differ in their recommendations. Those who adopt a descriptive account of disorder will not think that a person can be recovered merely by making it the case that his or her condition no longer causes harm. However, though they won't see harm-removal as being a route to recovery, they will almost certainly think it worthwhile on other grounds. This being said, if one adopts a value-laden account of disorder, interventions that reduce harm while leaving the functioning of subsystems untouched can be seen to be not merely good, but medical interventions (in that they can be judged to provide routes to recovery). In so far as many societies have a tendency to prioritise "medical" needs over other needs, whether an intervention can be understood as a route to recovery may make a difference to the resources allocated to it (as morally dubious as this may be).

\section{Models of recovery and measuring improvement}


Depending on the account of disorder one adopts, I have argued that there are many routes to recovery. This causes one obvious and serious problem. Patients are vulnerable to both exploitation and treatment side effects, and healthcare is expensive. This means that it is important to be able to evaluate which treatments are effective - as only effective treatments should be used. But if there are different ways to gaining recovery, and if recovery may depend on values, goals, social environment and so on, how can recovery or improvement be objectively measured?

Let's start by noting that measures of improvement and recovery are collected for different purposes. For example, sometimes the aim is to show that one drug works better than another. Sometimes funding for services has to be justified. Sometimes measures are considered when developing individual treatment plans. In these different contexts, different types of data may be appropriate and different worries must be met.

Let's consider the requirements of drug trials first. In comparing drug treatments the principal worry is that the drug may not be effective. Maybe drug companies are promoting drugs that don't actually produce beneficial effects, or are trying to sell a new drug that is actually no more efficacious than its predecessor. The way to test such claims is via large-scale drug trials. In this sort of context, ratings scales are needed that allow improvement to be rated objectively and in a standardized way across different contexts. At present, measures of symptomatology tend to be used. For example, in a study that examines the efficacy or effectiveness of antidepressant medication, a tool such as the Hamilton Depression Scale might be used to monitor symptom severity.

One might have many reasons for being concerned about such scales. Working out how the scales should be constructed is very difficult. How should symptoms be weighted? Are feelings of hopelessness more or less important than somatic symptoms in depression, for example? The exact phrasing of a question may 
make a difference - should a scale ask how often someone hears voices, or how often they are disturbed by voices, or both?

However, it is also important to note that when ratings scales are used to evaluate drugs there are very good reasons to try to avoid changing the scales. It is a good thing to be able to compare the effects brought about by new drugs with those brought about by old drugs and keeping the ratings scales the same increases the extent to which studies performed at different times and in different places can be compared.

On accounts of disorder that hold that disorders are necessarily bad there is a worry about using scales that measure symptoms without considering whether the symptom is harmful. Suppose that some people who hear voices continue to hear them but cease to be bothered by them. The fact that a voice hearer perceives a voice to be benevolent is not sufficient to show that the voice is harmless, as some apparently friendly voices may go on to demand suicide or violence (Rudnick 1999). However, let us suppose that at least some voices that are perceived by their hearers to be benevolent really do cause no harm. On accounts of disorder that claim that disorders are necessarily bad, in so far as voice hearing was the sole manifestation of their disorder, we may say that such persons have recovered. However, they will still gain a score on ratings scales that measure symptomatology.

The extent to which this causes problems in practice will depend on how common it turns out to be that symptoms such as voice hearing can cease to be harmful. If harmless voice-hearing is rare then continuing to use scales that treat voice hearing as if it were always problematic may not cause any difficulties. The unusual person who hears harmless voices would turn out to be statistically insignificant. Even if a fair number of voices can be rendered unproblematic the use of existing rating scales might still be justifiable. When evaluating drugs we might think of the basic problem being usefully split into two questions. First, we 
can ask, does the drug do anything? Then second, is whatever it does a good thing to do? Working out whether drugs do anything is a genuine problem, as it is highly plausible that pharmaceutical companies will try to sell inefficacious drugs if they can get away with it. Large scale studies using traditional ratings scales are the best known way to guard against such worries. However, when asking whether whatever the drug does is good, a different approach is required. Whether a drug does anything will largely be context invariant, but whether those drug effects are beneficial will depend on individual preferences and context. Take the slight extroversion sometimes caused by drugs such as Prozac. This may be useful in certain societies but problematic in societies that value more introverted personality traits (Carl Elliot suggests that SSRI use hasn't taken off in Japan for this reason (Elliott, 2004, pp. 70-76)). Only drugs that are efficacious should be candidates for use anywhere, but wisdom will still be required to select a drug that is likely to do good in a particular context (and to stop using it if it turns out not to be beneficial).

Traditional ratings scales should still be used in drug trials, but there are situations in which their use is less appropriate. A very different type of situation occurs when measures of improvement and recovery are sought to justify the funding of local services. Suppose that a service that seeks to find employment for persistently mentally ill people needs to justify its funding. In such cases the principal worry is that the service may be a waste of money. It is reasonable for such services to have to make a case that their outcomes are satisfactory, but the use of formal ratings scales may not be necessary or useful. Drug trials have to use quantifiable (and easily standardized) ratings because it is important to be able to aggregate and compare measures from very many patients. In evaluating small scale local services, gaining data that can be compared with data collected elsewhere will frequently be less important and will also be more difficult. Comparing outcomes across times and places can be expected to be problematic because the outcomes that a service can be expected to yield will vary radically with context. Whether a service that seeks to place mentally ill 
people in employment succeeds will depend on a whole range of contextual factors - success can be expected to vary with economic conditions, with changes in the levels of disability benefit, with factors such as the availability of transport to places of work, and so on.

The problems that arise when trying to evaluate the usefulness of local mental health services are not unique but occur when many types of public service are being evaluated. Comparing results across contexts is often impossible and it is frequently unclear what a service should seek to achieve. Consider the problems that emerge when we want to know if libraries serve a social good. We might measure how many people use them and how many books they borrow. But what if the people who use libraries would self-organise book swap clubs if public provision was cut? Or, what if most borrowed books turn out to be nasty racist tracts or pornographic? Or, what if many people turn out not to read the books they borrow but rather do it for social desirability reasons? As another example, after the 2001 riots in Bradford, UK, poets were employed to facilitate poetry writing workshops for disaffected young people. Rumour has it that at one public poetry reading a young man presented his work which included the line "Next time there's a riot I'm going to kill a policeman". Had the scheme succeeded? It's hard to say. If disaffected young people write violent poems, will this make them more or less likely to spend time fighting and setting fire to buildings? What if (as seems likely) the angry young men who write poems about killing aren't actually the same young men who are likely to engage in violence?

Evaluating services can be problematic, but many clearly improve lives at relatively little cost. If a service provides leisure activities for people who previously had nowhere to go, or it finds employment for people who were previously unemployed, then it's a fair bet that the service is a good thing. Quantitative outcomes, such as rates of employment, may be relevant and helpful in reaching such decisions, but seeking ratings that can reasonably be compared across contexts will often not be necessary or sensible. 
A third situation in which using measures of improvement and recovery may be necessary is in formulating individual treatment plans. Individual assessments are required to enable practitioners to discover what the problems of the patients are and to monitor the effectiveness of treatments. The goal of treatment should be to enable a patient to live a better life (or, in certain contexts, to reduce the extent to which a patient prevents others from living good lives). What sorts of measures might be used to assess whether the goal of improving a patient's quality of life is being achieved? On the one hand, using ratings of symptoms alone won't do. Improvements in someone's quality of life need not and often do not correlate with reductions in symptoms. Some symptoms may cause no problems. The weighting of the importance of symptoms will depend on the person's likes, goals, social context, and more, and non-illness related factors may make someone's life better or worse. Thus in monitoring the effectiveness of an individual's treatment, relying solely on ratings of symptomatology would be a mistake. On the other hand, just using measures that more directly assess quality of life, such as various scales of quality of life derived from the capabilities approach, would also be problematic. Someone's life might improve for many reasons - maybe he or she wins the lottery, or becomes a grandparent - and it only seems reasonable for courses of treatment to get credit for improvements for which the treatment can be considered causally responsible. If my life gets better while I'm taking psychoactive drugs, but this is because I inherit a nice big house, we don't want the improvement in my life to be taken as a sign that the drugs are working. To make things even more difficult, in many cases it may be unclear whether the cause of the improvement in someone's life is treatment related or not. Suppose I gain a lovely new boyfriend. It may not be possible to tell whether this is a stroke of good luck, or because my friends made an effort to introduce me to nice men, or because my medication has made me easier to get along with. 
What to do? As in the earlier discussion of drug trials, I suggest that it will be useful to carefully distinguish different questions. In monitoring treatment there can be two types of concern: 1 . Is the treatment doing anything? 2. Is whatever it is doing good? In monitoring whether a treatment is doing anything it's best to utilize a measure that is a fairly proximate effect of the treatment. This is because in monitoring outcomes there will always be uncertainty as to whether the effect has been brought about by the treatment or by some other factor, and the more proximate the effect the less chance there is that something else is doing the work. If after six weeks of antidepressant treatment my quality of life score goes up, this could be for any number of reasons. If my score on a symptoms-based rating scale goes down, this might also be for a variety of reasons, but the odds of the improvement being a drug-produced effect are increased. On the other hand, when it comes to considering whether whatever the treatment is doing is a good thing, measures of symptoms will not be sufficient, and quality-of-life based measures or qualitative judgment will have to be used (and given that self-report can be self-deceptive, these should include but not be limited to self-evaluations).

\section{Conclusion}

This chapter examined how one's view of what counts as recovery (in the sense whereby the recovered person is one who ceases to be disordered) will depend on the account of disorder that one adopts. On descriptive accounts of disorder, recovery is to be achieved via restoring functioning, and we have seen that this might be achieved at a variety of different levels (subsystem, organism, human-

plus-tools). On accounts of disorder that hold that disorders are necessarily bad it may be possible to get rid of disorders by making it the case that a state that previously caused harm ceases to do so. Depending on the account of disorder one adopts, there are thus many routes to recovery. If recovery can depend on values, and can thus be contingent on factors like goals, likes and dislikes, and social environment, one might expect that objectively measuring recovery or improvement would be problematic. I examined this worry in the final section of 
this chapter and I argued that one may think that recovery can depend on values and yet still employ traditional symptoms-based rating scales for certain purposes (most notably drug trials). The aim of this chapter is modest. I have merely sketched how one's account of disorder will have implications for one's account of recovery (as outcome). The large question of which account of disorder is correct has not been addressed here and requires further work.

\section{Acknowledgements}

I am grateful to Abraham Rudnick who read and commented on earlier versions of this chapter. A version of this paper was presented at a Philosophy of Psychiatry Work in Progress workshop held at Lancaster University, March 2011, and I am grateful for the comments of all those present.

\section{References}

Amundson, R. (2000). Against normal function. Studies in History and Philosophy of Biological and Biomedical Science, 31, 33-53.

Ariew, A., Cummins, R. and Perlman, M. (2002). Functions: New essays in the philosophy of psychology and biology. Oxford: Oxford University Press.

Bonney, S. and Stickley, T. (2008). Recovery and mental health: A review of the British literature. Journal of Psychiatric and Mental Health Nursing, 15, 140-153.

Boorse, C. (1975). On the distinction between disease and illness. Philosophy and Public Affairs, 5, 49-68.

Boorse, C. (1976a.). What a theory of mental health should be. Reprinted in R. Edwards (ed.) (1982). Psychiatry and Ethics. Buffalo, New York: Prometheus Books. pp. 29-48.

Boorse, C. (1977). Health as a theoretical concept. Philosophy of Science, 44, 542-573.

Boorse, C. (1997). A rebuttal on health. In J. Hunter and R. Almeder (eds.) What is Disease? Totowa, New Jersey: Humana Press. pp.1-134. 
Clark, A and Chalmers, D. (1998). The Extended Mind. Analysis, 58,10-23.

Cooper, R. (2002). Disease. Studies in History and Philosophy of Biological and Biomedical Sciences, 33, 263-282.

Cummins, R. (1975). Functional analysis. Journal of Philosophy, 72, 741-64.

Davidson, L., O'Connell, M ., Tondora, J., Lawless, M. and Evans, A. (2005).

Recovery in serious mental illness: A new wine or just a new bottle? Professional Psychology: Research and Practice, 36, 480-487.

Drayson, Z. and Clark, A. (forthcoming). Augmentation, agency and the spreading of the mental state. Neuroethics.

Dreger, A. (1998). Ambiguous sex - or ambivalent medicine? The Hastings Center Report, 28, 24-35.

Elliott, C. (2004). Better than Well: American medicine meets the American dream. New York: W.W. Norton and Company.

Fulford, K.W.M. (1989). Moral Theory and Medical Practice. Cambridge: Cambridge University Press.

Griffin, J. (1986). Well-being. Oxford: Clarendon Press.

Nordenfelt, L. (1987). On the Nature of Health: An action-theoretic approach. Dordrecht: Kluwer.

Nussbaum, M. (2000). Women and Human Development: The Capabilities Approach. Cambridge: Cambridge University Press.

Reznek, L. (1987). The Nature of Disease. London: Routledge and Kegan Paul.

Richman, K. (2004). Ethics and the Metaphysics of Medicine. Cambridge, Massachusetts: The MIT Press.

Rudnick, A. (1999). Relation between command hallucinations and dangerous behavior. Journal of the American Academy of Psychiatry and the Law. 27, 253257.

Sacks, O. (1995). An Anthropologist on Mars. London: Picador. 
Schrank, B. and Slade, M. (2007). Recovery in psychiatry. The Psychiatrist, 31, 321-325.

Sen, A. (1980). Equality of What? In S McMurrin (ed.) The Tanner Lecture on Human Values, vol. I. Cambridge: Cambridge University Press.

Sen, A. (1993). Capability and Well-being. In A. Sen and M. Nussbaum (eds.)

The Quality of Life, Oxford: Oxford University Press. Pp.30-53.

Slade, M. (2009). Personal Recovery and Mental Illness. Cambridge: Cambridge University Press.

Wakefield, J. (1992a.). The concept of mental disorder - On the boundary between biological facts and social value. American Psychologist, 47, 373-388.

Wakefield, J. (1992b.) Disorder as harmful dysfunction: A conceptual critique of D.S.M-III-R's definition of mental disorder. Psychological Review, 99, 232-247.

Wakefield, J. (1993). Limits of operationalization: A critique of Spitzer and Endicott's (1978) proposed operational criteria for mental disorder. Journal of Abnormal Psychology, 102, 160-172.

Wright, L. (1973), Functions. Philosophical Review. 82,139- 168. 